\title{
Real Exchange Rate Dynamics With Endogenous Distribution Costs*
}

\author{
Millan L. B. Mulraine ${ }^{\dagger}$ \\ University of Toronto
}

February 2007

\begin{abstract}
The importance of distribution costs in generating the deviation from the law of one price has been well documented. In this paper I demonstrate that a two-country flexible price dynamic general equilibrium model driven by exogenous shocks to technology, and with a localized distribution services sector can replicate the key dynamic features of the real exchange rate. In doing so, the paper identifies the importance of two key channels for real exchange rate dynamics. In particular, I show: (i) that shocks in the real sector are important contributors to movements in the real exchange rate, and (ii) that the endogenous wedge created by the distribution costs of traded consumer goods is a significant source of fluctuation for the real exchange rate, and the overall macro-economy. The evidence presented here shows that this model - without nominal rigidities, can generate significant variability and persistence in the real exchange rate, consistent with the empirical facts.
\end{abstract}

Keywords: Distribution costs, Real exchange rate dynamics, Law of one price.

JEL Classification: E31, F31, F41

${ }^{*}$ This paper forms part of my Ph.D. Economics thesis at the University of Toronto. I wish to thank G. Kambourov for his supervision of this effort, and the many others who offered helpful suggestions and comments. All remaining errors are mine.

${ }^{\dagger}$ Corresponding address: Department of Economics, University of Toronto, 150 St. George Street, Toronto, ON M5S 3G7, Canada. Tel: 1 (416) 824 8069, Email: millan.mulraine@utoronto.ca 


\section{Introduction}

In the international macroeconomics literature one puzzle remains as elusive today as it has been since its emergence thirty years ago. That is, since the beginning of the post-Bretton Woods flexible exchange rate period of 1971, nominal and real exchange rates have exhibited significant volatility and persistence, and have been considerably more variable than the underlying economic fundamentals assumed to be associated with their determination. As demonstrated in Table 1, for example, the bilateral nominal and real exchange rates of the currencies for the G6 countries relative to the US dollar are as much as nine times more volatile than output - with an average relative volatility of almost six. This puzzling behavior on the part of the exchange rate is commonly referred to as the "exchange rate disconnect" puzzle, see Obstfeld and Rogoff (2000). In addition to the high relative volatility observed, the nominal and real exchange rates also exhibit considerably high persistence, and are generally highly correlated with each other.

Following the publication of the Dornbusch (1976) 'overshooting' model ${ }^{1}$, the quest of the new open economy macroeconomics literature has been to explain the puzzling behavior of bilateral real exchange rates by means of dynamic general equilibrium monetary models with nominal rigidities in the form of sticky prices, à la Obstfeld and Rogoff (1995). This literature was further advanced by the monopolistic pricing-to-market model developed by Betts and Devereux (1996), which took account of the well established empirical observations on the pronounced deviations from the law of one price in traded goods - see Lane (2001) for an extensive survey of this literature.

This particular approach, however, is predicated on the assumption that the deviation in the law of one price is due exclusively to rigidities in the pricing structure for these traded goods and not the wedge created by their distribution costs. More importantly, the fundamental premise of this strand of the literature is that the dynamic behavior of the exchange rate is due to the interaction between shocks to the money supply and sticky prices - thereby obviating the role of technological innovations in determining the behavior of the real exchange

\footnotetext{
${ }^{1}$ In this elegant theoretical exposition it was shown that the volatile behavior of the exchange rate was consistent with rational expectations in the presence of price rigidities. The overshooting of the nominal exchange rate beyond its long-run level, therefore, was shown to be the result of the interaction between monetary shocks and sluggish price adjustment.
} 
rate, as postulated by the Balassa-Samuelson proposition ${ }^{2}$.

In an attempt to offer quantitative justifications for this approach, Chari et al. (2002) constructs a dynamic general equilibrium (DGE) monetary model to show that a model incorporating price stickiness for at least one year, high risk aversion, and separable preferences in leisure, can replicate the fluctuations in the real exchange rate between the US and a European aggregate. Indeed, while their model was able to account for the high volatility in the real exchange rate (relative to output), it was less successful in matching the associated high persistence. Moreover, they also show that adding real shocks (in the form of shocks to total factor productivity (TFP) and government spending) to their stylized model "change[s] the model predictions little" - thereby concluding that real shocks are not important in explaining the dynamics of the real exchange rate $^{3}$.

The empirical evidence on the dynamic behavior of the real exchange rate over the postBretton Woods floating exchange rate period, however, casts doubts on the importance of shocks to the money supply in explaining the deviation in the real exchange rate. Alexius (2005) shows that between $60-90 \%$ of the volatility of the real exchange rate can be accounted for by relative productivity shocks across trading partners, thereby providing evidence that confirms the long held view of a Balassa-Samuelson effect on the real exchange rate. In addition to this study, Carr and Floyd (2002) shows that the dynamic behavior of the USCanada real exchange rate, for example, can be explained by asymmetric real shocks, and that there appears to be no evidence to support the view that monetary shocks have had any significant impact.

Despite this evidence, the use of real quantitative general equilibrium models to explain the dynamic behavior of the real exchange rate has been largely absent from the international macroeconomics literature. This absence is largely due to the inability of the standard real DGE models to generate volatility and persistence in the real exchange rate that are consistent with the stylized facts. In this paper, I present evidence that confirms the Balassa-Samuelson proposition by positing a real DGE model with a localized distribution services sector, and

\footnotetext{
${ }^{2}$ The Balassa-Samuelson hypothesis, due to the work of Balassa (1964) and Samuelson (1964), asserts that an increase in the productivity of tradables relative to non-tradables in the home country, if larger than the relative productivity of its trading partner, will cause an appreciation in the real exchange rate.

${ }^{3}$ Kollman (2001) reaches a similar conclusion from his analysis of a small open economy with a comparable framework to Chari et al. (2002).
} 
in so doing provide an avenue for this strand of the literature to be further advanced.

The importance of distribution costs in generating the deviation from the law of one price has been well documented. In a seminal piece, Burstein et al. (2003) shows that distribution costs are very large, and can account for over $40 \%$ of the final price of retail goods in the US and over $60 \%$ in Argentina. These costs are related to services such as transportation, insurance, and marketing and other distribution services associated with bringing the internationally traded consumer good from the point of entry in the country to its final destination - the consumer. Conceptually, they are akin to the "iceberg costs" advocated by Obstfeld and Rogoff (2000). Consequently, to generate the deviations from the law of one price, this paper incorporates a localized distribution services sector. This technique departs fundamentally from the standard approach in the literature by treating distribution services as a productive activity that combines domestic labor and capital inputs with the imported consumer good to create a new domestically available consumer good. Thus, the model endogenously generates the wedge between the price of traded consumer goods between the two countries. The standard approach in the literature has been to assume that the consumption of a unit of imported consumer good requires a fixed proportion of the domestically produced consumer good.

In this paper I develop a stylized two-country DGE model driven solely by exogenous innovation to real factors in the economy to demonstrate that this model can replicate the dynamic behavior observed in the real exchange rate between the US and a European aggregate. In particular, I specify a non-monetary DGE model driven by shocks to investment-specific technology (IST), and with a localized distribution services sector to show that a stylized model without nominal rigidities can match the empirical facts on the real exchange rate. The inclusion of a distribution services sector enables us to endogenously generate the deviation from the law of one price which has been a key feature of the real exchange rate, and thus accounts for the contribution of the volatility in the real exchange rate made by movements in the distribution costs of traded consumer goods.

The main exogenous propagation mechanism considered in this paper is shocks to the efficiency of investment goods in the production of next period's capital goods - or investmentspecific technology shocks. To take account of this unique measure of productivity innovation, investment in machinery and equipment is directly affected by improved efficiency in their 
production of next period's capital stock. This form of innovation was shown by Greenwood et al. $(1988,2000)$ to account for over $30 \%$ of output fluctuation in the postwar US data. Further evidence on the impact of innovations to investment efficiency on the business cycle behavior of the US economy has been provided by Fisher (2006), who - using more recent data - finds that investment-specific technology shocks account for over $50 \%$ of business cycle variation in hours worked, compared to only $6 \%$ accounted for by shocks to total factor productivity. Boileau (2002) also uses this propagation mechanism in a two-country framework to explore its ability to explain the cross-country correlation of output and the terms of trade. ${ }^{4}$

In more recent work, Jin and Zeng (2005) develops a flexible price model propagated by shocks to both TFP and the money supply, and with distribution costs to show that with reasonably large distribution costs, their model can generate high volatility and persistence in the real exchange rate. Their model, however, was far less successful when it was simulated with only shocks to total factor productivity. This paper, differs from their work in a number of key dimensions. In this paper the innovation considered in this stylized economy comes from shocks to the efficiency of investment goods, and not the Solow-neutral total factor productivity shocks considered in their work. Secondly, and more importantly, in this paper I consider a distribution services sector instead of assuming that distribution costs are a fixed proportion of the price of traded consumer goods. And finally, in the model presented here, countries trade in not only consumption goods - as considered in their work, but also in intermediate capital good.

The remainder of the paper proceeds as follows. In Section 2 the model is presented with its dynamic features discussed in Section 3. In Section 4 the model solution is discussed, and the simulation results from the calibration of the model to match the stylized facts of the real exchange rate presented. The paper then concludes in Section 5.

\section{The Model Environment}

Consider a two-country, multi-sector general equilibrium open economy model in which each economy is comprised of three types of agents; a representative consumer, a representative

\footnotetext{
${ }^{4}$ Mulraine (2006) also uses this propagation mechanism in an small open economy framework to study the dynamic behavior of the Canadian economy.
} 
consumer goods producer, and a representative distribution services firm. The two economies considered are structurally symmetric, and as such, it will suffice to describe the agents and their activities in the home country, with an asterisk $\left(^{*}\right)$ denoting variables associated with the foreign country. These two economies are connected to each other through their trade in intermediate capital goods, consumer goods and financial assets.

\subsection{The Representative Consumer}

Each economy is populated by a large number of infinitely-lived identical agents of mass one who has taste for both domestic $\left(c_{1 t}\right)$ and foreign produced $\left(c_{1 t}^{m}\right)$ consumer goods. Each period the agent is endowed with a unit supply of labor which is divided among the two competing productive activities - the production of consumer goods $l_{c t}$, and the production of distribution services $l_{d t}$. Labor is considered to be perfectly mobile across the two productive sectors, but will be completely immobile across countries. The representative consumer chooses consumption $c_{t}$ to maximize their expected discounted utility function expressed by:

$$
E_{0} \sum_{t=0}^{\infty} \beta^{t} \log \left(c_{t}\right), \quad 0<\beta<1
$$

where $c_{t}$ is the consumption level of the composite consumer good which comprises of home and imported final consumption goods. The composite consumption good $c_{t}$ is such that:

$$
c_{t}=G\left(c_{1 t}, c_{1 t}^{m}\right)
$$

where I aggregate home produced $c_{1 t}$ and imported $c_{1 t}^{m}$ final consumption goods using a constant elasticity of substitution (CES) aggregator function $G\left(c_{1 t}, c_{1 t}^{m}\right)$ given by:

$$
G\left(c_{1 t}, c_{1 t}^{m}\right)=\left[\omega_{c}\left(c_{1 t}\right)^{\eta_{c}}+\left(1-\omega_{c}\right)\left(c_{1 t}^{m}\right)^{\eta_{c}}\right]^{\frac{1}{\eta_{c}}}
$$

This functional form of the CES aggregator enables us to characterize the respective preferences for home goods (or home bias) given by $\omega_{c}$ relative to imported consumption goods, and the constant elasticity of substitution between home and foreign produced final goods, $\sigma_{c}=\frac{1}{1-\eta_{c}}$.

The representative household has access to a perfectly competitive international capital market where they can trade in international financial assets $a_{t}$ at the endogenously determined risk-free world interest rate $r_{t}$. The accumulation of this type of financial asset will 
evolve according to the following process:

$$
a_{t+1}=t b_{t}+\left(1+r_{t}\right) a_{t}
$$

where $t b_{t}$ is the trade balance for the given period.

Each period, after observing the productivity shock, the representative consumer devotes $i_{t}$ of total income to gross investment, which is used towards the creation of intermediate capital goods. This shock - captured by $q_{t}$, represents an exogenous innovation to the efficiency of investment goods ${ }^{5}$ in the creation of the total domestic stock of intermediate capital goods given by $m_{t}=q_{t} i_{t}$. The stock of domestic intermediate goods, $m_{t}$, is then divided between the portion used domestically for the production of next period capital stock, $i_{1 t}$, and the portion $i_{1 t}^{*}$, which is exported to the foreign country, such that, $m_{t}=i_{1 t}+i_{1 t}^{*}$. The total domestic net investment in the capital stock for the current period $x_{t}$ involves a combination of domestic $i_{1 t}$ and foreign (imported) intermediate capital goods $i_{2 t}$. Such that:

$$
x_{t}=H\left(i_{1 t}, i_{2 t}\right)
$$

where I aggregate home and foreign intermediate goods using a constant elasticity of substitution (CES) aggregator function $H\left(i_{1 t}, i_{2 t}\right)$, such that:

$$
H\left(i_{1 t}, i_{2 t}\right)=\left[\omega_{k}\left(i_{1 t}\right)^{\eta_{k}}+\left(1-\omega_{k}\right)\left(i_{2 t}\right)^{\eta_{k}}\right]^{\frac{1}{\eta_{k}}}
$$

Similar to the composite consumption goods outlined above, this functional for the intermediate good aggregator characterizes the respective preference for home goods (or home bias) given by $\omega_{k}$ relative to foreign goods, and the constant elasticity of substitution between home and foreign produced final goods, $\sigma_{k}=\frac{1}{1-\eta_{k}}$.

The representative consumer purchases the output of the consumer goods firm $y_{c t}$ and the output of the distribution goods firm $c_{1 t}^{m}$ from the available income for that period. In addition to trade in the intermediate capital goods, the consumer exports domestically produced consumer goods $c_{1 t}^{*}$ and trades in foreign assets $a_{t}$. As such, the reduced-form budget

\footnotetext{
${ }^{5}$ Following the work of Greenwood et al. (2000), this paper espouses the use of capital-embodied technological changes as the main contributor to economic fluctuations in the economy considered. For an elaborate and exhaustive discussion on the issues related to the use of shocks to the efficiency of investment goods as a measure of technological innovation, see Fisher (1999).
} 
constraint for the representative consumer is given by:

$$
c_{1 t}+p_{1 t}^{m} c_{1 t}^{m}+p_{k t} i_{1 t}+p_{k t}^{*} i_{2 t}+t b_{t}+\left(\frac{\phi_{a}}{2}\right)\left(a_{t+1}-\bar{a}\right)^{2} \leq w_{t}+r_{t} k_{t}
$$

Subject to the following function which captures the evolution of the capital stock - net of the capital adjustment costs:

$$
k_{t+1}=(1-\delta) k_{t}+x_{t}-\left(\frac{\phi_{k}}{2}\right)\left(k_{t+1}-k_{t}\right)^{2}
$$

Where the variable $x_{t}$ captures the value of net investment added to the non-depreciated closing stock of capital in period $t$. Capital adjustment costs are generally introduced in models of this type as a mechanism for smoothing the reallocation of wealth between physical capital and the foreign asset holdings in response to temporary differentials in the net rate of return between foreign and domestic assets. As a result, the adjustment cost can be seen as the cost associated with the installation of new machinery and equipment. This cost could be considered to include training, installation fees and the cost of disposing of the old stock of machinery. The essential thing to note here, however, is that this cost will act as a moderating force on the investment decision of domestic agents, thereby eliminating excessive responsiveness in investment decisions to small rate differentials, and to ensure that any adjustment to the capital stock is gradual.

Following Schmitt-Grohé and Uribe (2003), I introduce a convex portfolio adjustment cost

given by $\left(\frac{\phi_{a}}{2}\right)\left(a_{t+1}-\bar{a}\right)^{2}$ to prevent agents from playing Ponzi-type games, and consequently ensuring stationarity in the behavior of net foreign asset holdings. In this framework, given the symmetric nature of the two economies considered the steady-state value of net foreign asset is assumed to be zero, that is $(\bar{a}=0)$.

\subsection{The Representative Final Goods Firm}

The home country produces an internationally tradeable composite consumption commodity whose Cobb-Douglas production technology is given by:

$$
y_{c t}=k_{c t}^{\alpha} l_{c t}^{1-\alpha}
$$

Where $k_{c t}$ and $l_{c t}$ represent the amount of capital and labor services which are allocated to this sector, respectively. Thus, the static profit maximization problem for this representative 
consumption good producer in the home country is given by:

$$
\max \pi_{t}^{c}=y_{c t}-w_{t} l_{c t}-r_{t} k_{c t}
$$

Note that the constant returns to scale technology for this consumptions goods firm necessitates that it makes zero profit.

\subsection{The Localized Distribution Sector Firm}

As outlined above, the imported consumer good requires the services of the local distribution services sector. I follow Burstein et al. (2003) in assuming that non-traded domestically produced commodities require no distribution services since the most important components of this expenditure are housing, health and education services. The representative distribution services sector firm, therefore, provides all the requisite services that are entangled in the movement of the imported consumption goods $c_{2 t}$ from its 'point of entry' in the home economy to the 'point of consumption' $c_{1 t}^{m}$. These services include transportation, advertising, insurance, warehousing and all other services associated with bringing the imported goods from the border to the retail outlet. In accordance with the findings of Burstein et al. (2004), I also abstract from having traded investment goods requiring any distribution services, since they have shown that the share of distribution services in the retail prices of investment good is very low. As a result, the profit maximization problem for this sector is given by:

$$
\max \pi_{t}^{d}=p_{1 t}^{m} c_{1 t}^{m}-w_{t} l_{d t}-r_{t} k_{d t}-p_{2 t} c_{2 t}
$$

subject to the following technology:

$$
c_{1 t}^{m}=\left[\omega_{d}\left(y_{d t}\right)^{\eta_{d}}+\left(1-\omega_{d}\right)\left(c_{2 t}\right)^{\eta_{d}}\right]^{\frac{1}{\eta_{d}}}
$$

In this regard, the distribution services firm takes the imported consumer goods $c_{2 t}$ and augments it with distribution services $y_{d t}$ before making it available at the consumer outlet as $c_{1 t}^{m}$. The production function for the distribution service is given by the following function:

$$
y_{d t}=k_{d t}^{\alpha} l_{d t}^{1-\alpha}
$$

One key feature of this framework is the fact that the distribution costs associated with the movement of the imported consumer good from the border to domestic consumers in this 
model $\left(\phi_{t}^{d}=p_{1 t}^{m}-p_{2 t}\right)$ arise endogenously, a departure from the standard literature where these costs are considered to be fixed and exogenous. Note that the distribution firm pays $p_{2 t}$ at the border for the imported consumption good and sells it at $p_{1 t}^{m}$ to home consumers. The constant returns to scale technology for the representative distribution services firm ensures that profits are zero, and consequently the retail price of the imported consumer good includes no mark-up. As before, the functional for the imported good aggregator characterizes the respective share of the imported good accounted for by distribution services given by $\omega_{d}$ relative to the final imported consumer good, and the constant elasticity of substitution between distributions services and foreign produced final goods, $\sigma_{d}=\frac{1}{1-\eta_{d}}$.

\subsection{The Real Exchange Rate}

To assess the dynamic properties of the real exchange rate of this stylized model I shall use two definitions of the real exchange rate. The first of which will be the real exchange associated with consumer prices. Recall that the representative consumer in both economies consumes two types of consumer goods - domestically produced consumer goods and the imported consumer good - given by $c_{1 t}$ and $c_{1 t}^{m}$, respectively, for the domestic consumer, and $c_{2 t}$ and $c_{2 t}^{m}$ for the foreign consumer. The prices associated with these commodities are $p_{1 t}$ (normalized to 1) and $p_{1 t}^{m}$, for the domestic consumer, and $p_{2 t}$ and $p_{2 t}^{m}$ for the foreign consumer. As such, given that the CES functional form of utility considered, the CPI for the home country $p_{t}^{c}$ and the foreign economy $p_{t}^{c, *}$ are given by:

$$
\begin{aligned}
p_{t}^{c} & =\left[\omega_{c}^{\frac{1}{1-\eta_{c}}}\left(p_{1 t}\right)^{\frac{\eta_{c}}{\eta_{c}-1}}+\left(1-\omega_{c}\right)^{\frac{1}{1-\eta_{c}}}\left(p_{1 t}^{m}\right)^{\frac{\eta_{c}}{\eta_{c}-1}}\right]^{\frac{\eta_{c}-1}{\eta_{c}}} \\
p_{t}^{c, *} & =\left[\omega_{c}^{\frac{1}{1-\eta_{c}}}\left(p_{2 t}\right)^{\frac{\eta_{c}}{\eta_{c}-1}}+\left(1-\omega_{c}\right)^{\frac{1}{1-\eta_{c}}}\left(p_{2 t}^{m}\right)^{\frac{\eta_{c}}{\eta_{c}-1}}\right]^{\frac{\eta_{c}-1}{\eta_{c}}}
\end{aligned}
$$

If the law of one price for the traded consumer goods were to hold, then we would expect the consumer price of the traded consumer goods to be such that $p_{2 t}=p_{1 t}^{m}$ and $p_{1 t}=p_{2 t}^{m}=1$. Following Betts and Kehoe (2001), I obtain an expression for the real exchange rate associated with consumer prices as:

$$
\operatorname{rer}_{t}^{c}=\frac{p_{t}^{c, *}}{p_{t}^{c}}
$$

Similarly, I can derive the the real exchange associated with the intermediate capital good

- based on producer prices. Recall that the representative consumer in both economies uses 
two types of intermediate capital goods in the production of next period's capital goods domestically produced investment good and the imported investment good - given by $i_{1 t}$ and $i_{2 t}$, respectively for the home consumer, and $i_{2 t}^{*}$ and $i_{1 t}^{*}$ for the foreign consumer. The prices associated with these commodities are $p_{k t}$ and $p_{k t}^{*}$, for the domestic consumer, and $p_{k t}^{*}$ and $p_{k t}$ for the foreign consumer. As such, given that the CES functional form of investment, the PPI for the home country $p_{t}^{k}$ and the foreign economy $p_{t}^{k, *}$ are given by:

$$
\begin{aligned}
p_{t}^{k} & =\left[\omega_{k}^{\frac{1}{1-\eta_{k}}}\left(p_{k t}\right)^{\frac{\eta_{k}}{\eta_{k}-1}}+\left(1-\omega_{k}\right)^{\frac{1}{1-\eta}}\left(p_{k t}^{*}\right)^{\frac{\eta}{\eta-1}}\right]^{\frac{\eta_{k}-1}{\eta_{k}}} \\
p_{t}^{k, *} & =\left[\omega_{k}^{\frac{1}{1-\eta_{k}}}\left(p_{k t}^{*}\right)^{\frac{\eta_{k}}{\eta_{k}-1}}+\left(1-\omega_{k}\right)^{\frac{1}{1-\eta_{k}}}\left(p_{k t}\right)^{\frac{\eta_{k}}{\eta_{k}-1}}\right]^{\frac{\eta_{k}-1}{\eta_{k}}}
\end{aligned}
$$

We obtain an expression for the real exchange rate associated with producer prices as:

$$
\operatorname{rer}_{t}^{k}=\frac{p_{t}^{k, *}}{p_{t}^{k}}
$$

\subsection{Stochastic Processes}

To close the model setup the propagation mechanism for the shocks to IST is described by the following processes:

$$
\mathbf{q}_{t+1}=\Gamma_{q} \mathbf{q}_{t}+\xi_{t}^{q}
$$

Where $\mathbf{q}=\left[\ln (q), \ln \left(q^{*}\right)\right]^{\prime}$. Here $\Gamma_{q}$ is the matrix of coefficients, and $\xi_{q}$ is the vector of mean zero normal random variables with contemporaneous variance-covariance matrix given by $\Sigma_{q}$, corresponding to the innovations to IST.

\subsection{Model Behavior}

In order to provide intuition into the model's behavior I shall briefly analyze the main channels of operation present. Recall that the dynamic behavior of this model hinges on two key features incorporated in this framework, namely: (i) the distribution services sector, and (ii) trade in both consumer and intermediate capital goods. The first of these features provides the natural wedge between the domestic and foreign price of traded consumer goods - or the deviation from the law of one price in traded goods. This endogenous wedge arises from the fact that imported consumer goods must first be augmented with domestic distribution services before they are consumed by agents in the model. 
The role of distribution services in the model is quite simple, but significant. Its existence means that the price of the same commodity across the two countries will differ by the cost of providing the requisite distribution services. As a consequence of this difference in the price across the two countries for traded consumption goods, movements in the price of a unit of distribution service will result in deviation in the relative price of traded consumer goods across the two countries, and hence deviations in the real exchange rate via a difference in the aggregate price index of the respective economies. The endogenous nature of this sector means that this wedge will vary with relative prices, and will not be constant as is the standard in the literature. Moreover, because the aggregate consumer good requires both domestic and foreign produced consumer goods, the income effect from the productivity innovation will ensure the persistence in distribution costs of the imported consumer good - and consequently, the real exchange rate.

The trade in both producer and consumer goods - with only consumer goods requiring distribution services, provides another key conduit through which any propagation can have divergent impacts across the two economies. Foremost among these will be its impact on the consumption and investment decision of agents during the period in which the shock occurs. Because the final consumption $c_{t}$ and investment $x_{t}$ good requires a mix of domestic and foreign produced goods, and with the elasticity of substitution between these goods being constant, there will be opportunities for technology and wealth sharing across the two economies as a result of asymmetric shocks. As a consequence of this, this feature will mitigate against risk-pooling across countries, which an otherwise standard two-country model will engender.

For example, consider a unit shock to investment efficiency in the domestic economy relative to the foreign economy. The first-period wealth effect from this innovation will result in increased consumption and investment for domestic agents, while the substitution effect will favor accumulation of investment goods relative to consumption goods. The decrease in consumption will favor the importation of the relatively cheaper foreign-produced consumer goods, while the increase in capital will result in the creation of more domestic intermediate capital goods. To finance these additional expenditure, domestic agents will inevitably borrow against the higher rate of return from capital in the future. Clearly, the ramifications of these two effects cannot be fully analyzed in this stochastic model as they will affect not only 
the quantities traded, but also the prices of these commodities traded and consequently, the aggregate price level. As a result I shall now turn to the numerical solution to the model.

\section{Recursive Problem for the Home Economy}

Let $V\left(k, k^{*}, a, q, q^{*}\right)$ be the value function for the representative agent, whose assets at the beginning of the period are given by the holding of foreign assets $a$, and the stock of capital $k$, and who faces the equilibrium wage and rental rate of capital given by $w$ and $r$, respectively. Let the aggregate state of the world facing this representative agent be described by $\lambda\left(k, k^{*}, a, q, q^{*}\right)$, where $A(\lambda)$ and $K(\lambda)$ are the aggregate holding of assets, and $P(\lambda), R(\lambda)$, and $W(\lambda)$ are the aggregate vector of prices, and the equilibrium rental price for capital and labor, respectively. The dynamic problem facing the representative agent of the home econ-

omy $^{6}$ who takes the aggregate state of the world as given can be represented by the following Bellman equation:

$$
V\left(k, k^{*}, a, q, q^{*}\right)=\max _{a^{\prime}, c_{1}, c_{1}^{m}, c_{2}, i_{1}, i_{2}, k^{\prime}, k_{c}, l_{c}}\left\{\log (c)+\beta E\left[V\left(k^{\prime}, k^{*^{\prime}}, a^{\prime}, q^{\prime}, q^{*^{\prime}}\right)\right]\right\}
$$

subject to:

$$
\begin{gathered}
c_{1}+p_{2} c_{2}+p_{k} i_{1}+p_{k}^{*} i_{2}+t b+\left(\frac{\phi_{a}}{2}\right)\left(a^{\prime}-\bar{a}\right)^{2} \leq y_{c} \\
t b=a^{\prime}-(1+r) a \\
l_{c}+l_{d} \leq 1 \\
k_{c}+k_{d} \leq k \\
k^{\prime}=(1-\delta) k+x-\left(\frac{\phi_{k}}{2}\right)\left(k^{\prime}-k\right)^{2} \\
x=\left[\omega_{k}\left(i_{1}\right)^{\eta_{k}}+\left(1-\omega_{k}\right)\left(i_{2}\right)^{\eta_{k}}\right]^{\frac{1}{\eta_{k}}} \\
c=\left[\omega_{c}\left(c_{1}\right)^{\eta_{c}}+\left(1-\omega_{c}\right)\left(c_{1}^{m}\right)^{\eta_{c}}\right]^{\frac{1}{\eta_{c}}} \\
c_{1}^{m}=\left[\omega_{d}\left(y_{d}\right)^{\eta_{d}}+\left(1-\omega_{d}\right)\left(c_{2}\right)^{\eta_{d}}\right]^{\frac{1}{\eta_{d}}} \\
y_{c}=k_{c}^{\alpha} l_{c}^{1-\alpha} \\
y_{d}=k_{d}^{\alpha} l_{d}^{1-\alpha}
\end{gathered}
$$

\footnotetext{
${ }^{6} \mathrm{~A}$ symmetric recursive problem exists for the foreign country.
} 
and

$$
q^{\prime}=\rho_{q} q+\rho_{q, q^{*}} q^{*}+\varepsilon_{q}
$$

\subsection{Competitive Equilibrium for the World Economy}

A competitive equilibrium for the decentralized world economy is a vector of prices $\mathrm{P}\left(p_{1}^{m}\right.$, $\left.p_{2}^{m}, p_{2}, p_{k}, p_{k}^{*}, r, w w^{*}\right)^{7}$, and allocations $\left(a^{\prime}, k^{\prime}, c_{1}, c_{1}^{m}, c_{2}, i_{1}, i_{2}, k_{c}, k_{d}, l_{c}, l_{d}\right)$ for the home country, and $\left(k^{*^{\prime}}, c_{1}^{*}, c_{2}^{m}, c_{2}^{*}, i_{1}^{*}, i_{2}^{*}, k_{c}^{*}, k_{d}^{*}, l_{c}^{*}, l_{d}^{*}\right)$ for the foreign country such that:

1. The representative household in the home and foreign country solves their respective problem taking the aggregate state of the world $\lambda($.$) and the vector of aggregate prices P($. as given, with the optimal allocations to their problem satisfying $a^{\prime}=A^{\prime}(\lambda), c_{1}=C_{1}(\lambda)$, $c_{1}^{*}=C_{1}^{*}(\lambda), c_{1}^{m}=C_{1}^{m}(\lambda), c_{2}^{m}=C_{2}^{m}(\lambda), i_{1}=I_{1}(\lambda), i_{1}^{*}=I_{1}^{*}(\lambda), i_{2}=I_{2}(\lambda), i_{2}^{*}=I_{2}^{*}(\lambda)$, $k^{\prime}=K^{\prime}(\lambda)$ and $k^{*^{\prime}}=K^{*^{\prime}}(\lambda)$;

2. Given prices, the allocations $l_{c}=L_{c}(\lambda), l_{c}^{*}=L_{c}^{*}(\lambda), k_{c}=K_{c}(\lambda)$ and $k_{c}^{*}=K_{c}^{*}(\lambda)$, solve the profit maximization problems for the representative consumer goods producers in the home and foreign economy.

3. Given prices, the quantities $c_{2}=C_{2}(\lambda), c_{2}^{*}=C_{2}^{*}(\lambda), l_{d}=L_{d}(\lambda), l_{d}^{*}=L_{d}^{*}(\lambda)$, $k_{d}=K_{d}(\lambda)$ and $k_{d}^{*}=K_{d}^{*}(\lambda)$ solves the profit maximization problems for the representative distribution services firms in the home and foreign economy.

4. All factors and goods markets clear.

5. The global goods and asset markets ${ }^{8}$ clear. Such that:

$$
t b+t b^{*}=0
$$

\section{Quantitative Assessment}

Having fully specified the model, I shall now turn to the quantitative assessment of its properties. Note that due to the stochastic nature of the model specification, the competitive

\footnotetext{
${ }^{7}$ All prices considered in this model economy are expressed relative to the price of the domestically produced consumer good $p_{1}$ - which has been normalized to 1 . As such, the relative price of the traded intermediate goods $i_{1}$ for the home country and $i_{2}$ for the foreign country, are given by $p_{k}=\frac{1}{q}$ and $p_{k}^{*}=\frac{p_{2}}{q^{*}}$, respectively. Note that these prices correspond to the relative price of investment goods in the respective economies.

${ }^{8}$ The trade balance (or net exports) for the home economy is given by $t b=c_{1}^{*}+p_{k} i_{1}^{*}-p_{2} c_{2}-p_{k}^{*} i_{1}$. As such, the balance of payment can be expressed by $t b+r a-\left(a^{\prime}-a\right)=0$.
} 
equilibrium allocations do not have closed-form analytical solutions. Thus, the model must be solved numerically. This will be done by finding an approximate solution to the log-linear approximation of the first order conditions about their steady-state values. The approach used here is akin to the method advocated by King et al. (1988), and is similar to that used by Schmitt-Grohé and Uribe (2003). A complete discussion of the solution to this model, and the derivation of its steady-state properties is provided in Appendix A.1 - A.3. The moments used in this analysis are the relative percentage standard deviation - that is, the standard deviations of the macroeconomics variables of interest relative to the standard deviation of GDP, the first-order autocorrelation of each variable of interest, and their respective cross-country correlation.

\subsection{Parameter Calibration}

Since the two economies considered in this framework are symmetric in all respects, all the parameters used in the calibration have the same value in both economies ${ }^{9}$. In Table 4 I provide a complete summary of all parameter values used. The constant discount factor is set at $\beta=0.96$ corresponding to an annual steady-state interest rate of $r^{*}=0.04$, and the constant depreciation rate for capital was set at $\delta=0.10$. Following Backus et al. (1994), for the benchmark model the value of the elasticity of substitution between home and foreign consumer goods, distribution services and imported consumer goods, and the home and imported intermediate capital goods were set to $\sigma_{c}=\sigma_{d}=\sigma_{k}=1.5$, such that $\eta_{c}=\eta_{d}=\eta_{k}=1 / 3$, respectively ${ }^{10}$.

To determine the share parameter values for domestic consumption goods, intermediate capital goods, and distribution services given by $\omega_{c}, \omega_{k}$ and $\omega_{d}$, respectively, I follow the calibration procedure of Boileau (2002) who set the steady-state output share of trade in final goods and trade in equipment to $20 \%$ and $10 \%$, respectively. In addition to these trade shares, following the findings of Burstein et al. (2003), I also simultaneously set the steady-state distribution margin for imported consumer goods equal to $42 \%$ - equivalent to a

\footnotetext{
${ }^{9}$ Following Boileau (2002), the model was calibrated and simulated at the annual frequency due to the fact that data on IST shocks are only available at this frequency.

${ }^{10}$ As a sensitivity check I provide the moments for two other values for the elasticity of substitution, given by $\sigma_{i}=2.0$ and $\sigma_{i}=2.5$.
} 
distribution margin for consumer goods in the US. As a result of this calibration procedure, I obtain the respective shares given by $\omega_{c}=0.710, \omega_{k}=0.720$ and $\omega_{d}=0.280$.

Following Boileau (2002), the productivity innovation to investment efficiency has a standard deviation of 0.013 and a cross-country correlation of 0.345 . The exogenous investmentspecific shocks process has a autocorrelation of 0.553 and a cross-country feedback of 0.027 . As such the matrices for $\Sigma_{q}$ and $\Gamma_{q}$ are given by.

$$
\boldsymbol{\Sigma}_{\mathbf{q}}=10^{-4}\left(\begin{array}{ll}
1.687 & 0.582 \\
0.582 & 1.687
\end{array}\right), \quad \boldsymbol{\Gamma}_{\mathbf{q}}=\left(\begin{array}{ll}
0.553 & 0.027 \\
0.027 & 0.553
\end{array}\right)
$$

Given the moments for the stochastic processes described above, the only remaining parameter to be determined in this model will be $\phi_{i}, \quad i \in\{a, k\}$ - the adjustment costs parameters. These parameters are particularly important since they determine (to a large extent) the investment and net foreign assets responses to innovations to the exogenous processes considered. Despite their significance, however, these parameters cannot be determined ex-ante as they have no empirical counterparts. As such, I set their values in a manner that will limit the volatility in investment, while simultaneously ensuring stationarity in all macroeconomic variables. To this end, I use a value of $\phi_{a}=0.50$ and $\phi_{k}=2.32$. This value for the capital adjustment cost is equivalent to the maximal value in the range of 1.50 and 2.32 advocated by Greenwood et al. (2000), and is the same value used by Boileau (2002).

\subsection{Simulation Results}

This section is primarily aimed at comparing the performance of the model presented in matching the dynamic properties of the data. To do this, particular attention will be paid to the ability of the model to match key moments in the data. That is, I shall examine the variability (relative volatility) ${ }^{11}$, first-order autocorrelation and cross-country correlation of total consumption, total investment, the ratio of net export to output, the CPI-based real exchange rate, and the PPI-based real exchange rate. Further analysis will be conducted by examining the associated dynamics of these variables of interest by studying the impulse responses generated from a $1 \%$ shocks to investment-specific technology in the home economy.

\footnotetext{
${ }^{11}$ I do not directly report the volatility of the variables of interest but instead follow the standard approach in the literature by reporting their volatility relative to the volatility of total output.
} 


\subsection{Benchmark Model}

The requisite unconditional moments generated from the simulation exercises are presented in Table 2 below. Column 2 of Table 2 refers to the associated annualized data for the US and a European aggregate obtained from Chari et al. (2002) for the period 1973-98 that has been logged and detrended using the HP filter. In Columns 3 I present the unconditional moments for the macroeconomic aggregates for the benchmark model, in which case the elasticity of substitution has been set to $\sigma_{i}=1.5$.

As seen in this column, the model can explain as much as $71 \%$ of the relative volatility of the CPI-based real exchange rate, with the relative volatility in the PPI-based real exchange rate being higher than that of its CPI-based counterpart. Moreover, it can also be seen that the model generates significant endogenous variability in distribution costs - with distribution costs being close to three time more volatile than output. The benchmark model also successfully matches the high persistence in the CPI-based real exchange rate, in contrast to the findings of Chari et al. (2002) where the model prediction was much lower. The link between distribution costs and the CPI-based real exchange rate in this model becomes discernable when one observes that the persistence for both variables is identical. This evidence points to the fact that in this model specification, distribution costs - and consequently, the deviation from the law of one price, are integral to the dynamic behavior of the CPI-based real exchange rate.

Despite this appealing performance, the model performs inadequately in matching the empirical variability of investment and consumption. As we can see in the table, the model overestimates the relative volatility of investment by a factor of 3 , and underestimates the relative volatility of consumption. The excessive volatility in investment emerges as a direct consequence of the nature of the technological innovation considered, and is similar to the outcome documented by Boileau (2002). Despite the excessive volatility, the model correctly replicates the persistence of investment. On the other hand, the persistence of consumption and output are considerably higher than their empirical counterparts.

In terms of the cross-country correlation of the macroeconomic aggregates, the benchmark model avoids the counterfactual negative cross-country correlation in investment - an outcome that has been the feature of standard international business cycle models. In essence, by 
incorporating trade in equipment, the innovation to investment-specific technology in the home country is exported to the foreign country which will invariably benefit from this new technology. This feature mitigates against the impact of risk-sharing in the form of financial asset flows to the country with the favorable productivity innovation, thereby eliminating the negative cross-country correlation in investment. Note also that the model does reasonably well in matching the high cross-country correlation of output.

One major anomaly that emerges from the work of Chari et al. (2002) is the inability of their model to replicate the correlation between relative consumption and the real exchange rate. In particular, their model generates a correlation of 1 between these two variables, compared to a statistic of -0.35 in the data. They refer to this discrepancy between the prediction of their model and the data as the "consumption-real exchange rate anomaly". In contrast to their results, as demonstrated in Table 2, this model not only avoids the counterfactual perfect correlation between the real exchange rate and relative consumption obtained by Chari et al. (2002), but also correctly replicates their negative relationship. Additionally, the model also replicates the empirical pro-cyclicality of the real exchange rate, and unlike Chari et al. (2002), is able to replicate the positive correlation between the real exchange rate and the trade balance.

The dynamic behavior of the variables of interest in the stylized model following a $1 \%$ shock to investment-efficiency in the home country - with the elasticity of substitution set to 1.5 - are presented in Figure 1 - Figure 3. Here we can ascertain the response of home (Figure 1) and foreign (Figure 2) macroeconomic aggregates, and prices, foreign assets and the trade balance (Figure 3). From these graphs, it becomes apparent that the shocks to the productivity of domestic investment goods along with trade in these intermediate capital goods result in an immediate accumulation of capital goods in both countries, though the level of accumulation in the home country where the shock occurred is twice that of its trading partner. The magnitude of the rise in net investment in the two countries, however, differs as the home country experiences a considerably higher increase in net investment than its trading partner. Consistent with economic theory, the home country substitutes the foreign intermediate goods for the more efficient and relatively cheaper domestic counterpart, while in the foreign country the local intermediate goods was substituted by the relatively cheaper imported intermediate investment goods. 
The behavior of total consumption in these two economies is also instructive. As is evident from the graph, total consumption falls slightly in the first period before rising above its steady-state level in the home country. Similar to the evidence on the behavior of investment accumulation, the level of consumption falls by a larger margin in the foreign country than in the home economy. In the home country the substitution effect dominated the wealth effect from the higher productivity shock as agents substitutes consumption in the initial period of the shock for investment goods which was used to financed the higher consumption (relative to its steady-state level) in subsequent periods. Note also that in the home country the greater increase in investment along with a smaller reduction in consumption relative to the foreign country is financed by the accumulation of foreign debts.

Figure 3 provides impulse responses for the various price levels, distribution costs and the domestic holding of net foreign assets to a $1 \%$ shock to productivity in the home country. As seen, the home country accumulates foreign debts (negative trade balance) which is used to finance its increased investment and consumption over the horizon of the analysis. Another key observation that emerges from these impulse responses is the similarity in the behavior of distribution costs and the CPI-based real exchange rate. As documented above by their identical persistence, both variables moved in a similar manner despite the fact that the magnitude of their movements were different - consistent with their respective volatility documented above. In addition to this I show that the home country experiences an appreciation in the CPI-based real exchange rate, consistent with the Balassa-Samuelson proposition.

\subsection{Sensitivity Analysis on the Elasticity of Substitution}

Following Backus et al. (1994), I simultaneously vary the three elasticities of substitution as a sensitivity check of the behavior of the benchmark model. In Column 4 of Table 2 I provide unconditional moments for the macroeconomic aggregates for the "mid-level elasticity" case given by $\sigma_{i}=2.0$, and in Column 5 I provide moments for the "high elasticity" case, $\sigma_{i}=2.5 .{ }^{12}$ The values for the adjustment costs parameters were maintained at the same level as in the benchmark model. Note also that to maintain the import shares and the distribution margin outlined above, the CES shares given by the $\omega_{i}$ 's must also be re-calibrated. The re-calibrated

\footnotetext{
${ }^{12}$ The associated impulse responses for these values of the elasticity of substitution are not shown.
} 
values are provided in Table 2 below.

The evidence provided in Table 2 shows that the ability of the model to match the relative volatility of the CPI-based real exchange rate diminishes as the elasticity of substitution increases. In the case of the "high elasticity" case the model matches $46 \%$ of the relative volatility of the CPI-based real exchange rate, compared to $71 \%$ in the benchmark case. However, the model maintains its ability to achieve the correlation between the real exchange rate and relative consumption consistent with the data. It also replicates the pro-cyclicality of the real exchange rate, in addition to the positive correlation between the real exchange rate and the trade balance.

\subsubsection{Elasticity of Substitution in the Distribution Services Sector}

As a final sensitivity check I vary the elasticity of substitution between distribution services and the imported consumer good, represented by $\sigma_{d}$. To do this I maintain the elasticity of substitution between consumption goods and that for intermediate capital goods to the benchmark value, such that $\sigma_{c}=\sigma_{k}=1.5$. The results from this exercise are present in Column $3\left(\sigma_{d}=1.45\right)$ and Column $4\left(\sigma_{d}=1.55\right)$ of Table 3, respectively. Here it becomes evident that the elasticity of substitution between distribution services and the imported consumer good is integrally important in determining the volatility and persistence of the CPI-based exchange rate. That is, ceteris paribus, the lower the elasticity of substitution between distribution services and the imported consumer good, the better is the performance of the model in matching the relative volatility of the real exchange rate. Conversely, when the elasticity of substitution between distribution services and the imported consumer good was increased to $\sigma_{d}=1.55$ the performance of the model in matching the relative volatility of the CPI-based exchange rate deteriorates.

\subsection{The Role of the Distribution Services Sector (Model II)}

To ascertain the role of distribution services in generating the dynamics in the real exchange rate in the benchmark model, I posit a more parsimonious model with a modified localized distribution services sector. That is, I assume that the quantity of distribution services required to augment the foreign-produced imported consumer goods $c_{2 t}$ in the production of 
the locally consumed imported good $c_{1 t}^{m}$ is a fixed proportion of the domestically produced consumer goods ${ }^{13}$. That is:

$$
d_{t}=\phi_{d} y_{t}
$$

Where $\phi_{d}$ was set equal to 0.02 to reflect the fact that in the steady-state of the benchmark model distribution services accounted for $2 \%$ of GDP. Note that in this framework the capital stock and the unitary supply of labor will be devoted entirely to the production of the tradeable consumer good. Moreover, for the sake of comparative purposes I maintained the parameterization used in the benchmark model. The results from this simulation exercise are presented in Column 5 of Table 3 below.

From the results presented in Column 5 of Table 3, it becomes apparent that the modified configuration generates far less volatility than in the benchmark model. In the case of the CPI-based real exchange rate, I have that the relative volatility is considerably smaller than in the benchmark model, while the volatility for distribution cost has fallen by a factor of just over 2. The reduction in the relative volatility of the CPI-based real exchange rate arises directly from the reduced volatility in the domestic price of the traded consumer good $p_{1 t}^{m 14}$ a direct consequence of the reduced volatility of the distribution costs. The disproportionate reduction in the relative volatility of the CPI-based real exchange rate compared to the relative volatility of the PPI-based real exchange rate results from the definition of the the CPI-based real exchange rate given by Equation 14 - 16. It is of interest to note that the excessively high persistence in the real exchange rates obtained in this model specification arises naturally from the assumption of the fixed distribution costs.

The modified model configuration also resulted in reduced relative volatility in investment. More generally, this model also correctly replicates the negative correlation between the exchange rate and relative consumption and the pro-cyclicality of the real exchange rate. The framework considered here, however, produces the wrong sign for the correlation between the real exchange rate and the trade balance. I also obtained, but do not report here, the impulse responses of the main macroeconomic variables of interest. The impulse responses for this model specification are similar in their dynamic behavior to the benchmark model, with the

\footnotetext{
${ }^{13}$ All the other features of the benchmark model were maintained.

${ }^{14}$ Recall that the domestic price of the imported consumer good $p_{1 t}^{m}=p_{2 t}+\phi_{t}^{d}$. Where $\phi_{t}^{d}$ is the distribution cost of producing $c_{1 t}^{m}$.
} 
main difference being in the magnitude of the responses.

\section{Conclusion and Extensions}

In this paper I show that - in contrast to the standard prediction in the literature, a model with shocks to investment-specific technology (IST), and propagated by a localized distribution services sector can account for up to $71 \%$ of the relative volatility in the real exchange rate, and generate persistence that are consistent with the empirical facts. These findings accord with the Balassa-Samuelson proposition, and provide evidence to show that real innovations in the economy can account for a significant portion of the empirical volatility of the real exchange rate, in accordance with the findings of Alexius (2005). Moreover, by incorporating the localized distribution services sector, the model has been able to endogenously generate the deviation in the price of the traded consumer goods in the two economies considered. In addition to generating dynamics consistent with the stylized facts on the real exchange rate, I have been able to show that a model with trade in intermediate capital goods can provide a resolution to the "consumption-real exchange rate anomaly" of Chari et al. (2002).

The model specification considered is motivated by the evidence on the importance of distribution costs in generating the deviation in the law of one price, and the long held view that productivity innovations play an important role in real exchange rate dynamics. It is aimed at providing an avenue for considering the contribution of innovation to productivity in explaining the real exchange rate - a facet of the literature that has been largely missing. In particular, the model departs from the use of the standard TFP shock model which has been shown by Kollman (2001) and Chari et al. (2002) to be ineffective in generating the requisite volatility in the real exchange rate.

The model offers a number of avenues for further extension. An interesting extension to the framework considered here will be to augment the IST shocks model with innovations to government spending, and to compare the performance of a model with these two sources of real innovations with those of a model driven by innovations to the money supply. It also affords us with the ability to directly explore the role of distribution services in real exchange rate determination, and the macro-economy as a whole. Given that this framework offers directly testable predictions on the dynamic behavior of distribution costs, it would also be 
interesting to take this model to the data to compare it prediction on the dynamic behavior of distribution costs to it empirical counterpart. 


\section{References}

Alexius, A. (2005). Productivity shocks and real exchange rates. Journal of Monetary Economics, 52:555-566.

Backus, D. K., Kehoe, P. J., and Kydland, F. E. (1994). Dynamics of the trade balance and the terms of trade: The J-curve. The American Economics Review, 84:84-103.

Balassa, B. (1964). The purchasing power parity doctrine: A reappraisal. The Journal of Political Economy, 72:584-596.

Betts, C. and Devereux, M. B. (1996). The exchange rate in a model of pricing-to-market. European Economic Review, 40:1007-1021.

Betts, C. and Kehoe, T. (2001). Tradability of goods and real exchange rate fluctuations. FRBM, Research Department Staff Report.

Boileau, M. (2002). Trade in capital goods and investment-specific technical change. Journal of Economic Dynamics and Control, 26:963-984.

Burstein, A. T., Neves, J. C., and Rebelo, S. (2003). Distribution costs and real exchange rate dynamics during exchange-rate-based stabilizations. Journal of Monetary Economics, $50(1189-1214)$.

Burstein, A. T., Neves, J. C., and Rebelo, S. (2004). Investment prices and exchange rates: Some basic facts. Journal of the European Economic Association, 2(2-3):302-309.

Carr, J. L. and Floyd, J. E. (2002). Real and monetary shocks to the Canadian dollar: Do Canada and the United States form an optimal currency area? North American Journal of Economics and Finance, 13:21-39.

Chari, V. V., Kehoe, P. J., and McGratten, E. R. (2002). Can sticky price models generate volatile and persistent real exchange rate? Review of Economic Studies, 69:533-563.

Dornbusch, R. (1976). Expectations and real exchange rate changes. Journal of Political Economy, 84:1161-1176. 
Fisher, J. D. M. (1999). The new view on growth and business cycles. Economic Perspectives, $23(1): 34-56$.

Fisher, J. D. M. (2006). The dynamic effects of neutral and investment-specific shocks. Journal of Political Economy, 144(3):413-451.

Greenwood, J., Hercowitz, Z., and Huffman, G. W. (1988). Investment capacity utilization, and the real business cycle. The American Economic Review, 78:402-417.

Greenwood, J., Hercowitz, Z., and Krusell, P. (2000). The role of investment-specific technological change in the business cycle. European Economic Review, 44:91-115.

Jin, Y. and Zeng, Z. (2005). Volatile and persistent exchange rates: How important are distribution costs? Mimeo.

King, R. G., Plosser, C. I., and Rebelo, S. T. (1988). Production, growth and business cycles, I: The basic neoclassical model. Journal of Monetary Economics, 21:196-232.

Kollman, R. (2001). The exchange rate in a dynamic-optimizing business cycle model with nominal rigidities: A quantitative investigation. Journal of International Economics, $55: 243-262$.

Lane, P. R. (2001). The new open econoomy macroeconomics: A survey. Journal of International Economics, 54:235-266.

Mulraine, M. L. B. (2006). Investment-specific technology shocks in a small open economy. University of Toronto, Mimeo.

Obstfeld, M. and Rogoff, K. (1995). Exchange rate dynamics redux. Journal of Political Economy, 103(3):624-660.

Obstfeld, M. and Rogoff, K. (2000). The six puzzles in international economics: Is there a common cause? NBER Macroeconomics Annual 2000, 15(1):339-390.

Samuelson, P. A. (1964). Theoretical notes on trade patterns. The Review of Economics and Statistics, 23:145-154. 
Schmitt-Grohé, S. and Uribe, M. (2003). Closing the small open economy model. Journal of International Economics, 61:163-185. 
Table 1: Stylized facts on G6 Exchange Rates Relative to the US\$, 1973-1995

Canada: France: Germany: Italy: Japan: U. K.: Mean:

Volatilities:

$\begin{array}{lccccccc}\text { Output } & 2.569 & 1.554 & 2.114 & 2.015 & 2.118 & 2.627 & 2.166 \\ \text { Real Exchange Rate } & 5.247 & 14.584 & 13.444 & 14.456 & 11.869 & 12.996 & 12.099 \\ \text { Nominal Exchange Rate } & 5.718 & 12.993 & 12.744 & 12.490 & 12.766 & 13.095 & 11.634\end{array}$

\section{Relative Volatility:}

$\begin{array}{llllllll}\text { Real Exchange Rate } & 2.043 & 9.384 & 6.358 & 7.176 & 5.605 & 4.947 & 5.919 \\ \text { Nominal Exchange Rate } & 2.226 & 8.360 & 6.027 & 6.200 & 6.029 & 4.984 & 5.638\end{array}$

\section{Persistence:}

$\begin{array}{llllllll}\text { Real Exchange Rate } & 0.627 & 0.670 & 0.665 & 0.658 & 0.446 & 0.505 & 0.595 \\ \text { Nominal Exchange Rate } & 0.645 & 0.650 & 0.665 & 0.637 & 0.518 & 0.536 & 0.608\end{array}$

\section{Cross-Correlation:}

\begin{tabular}{llllllll} 
NER \& RER & 0.952 & 0.989 & 0.986 & 0.983 & 0.954 & 0.962 & 0.971 \\
\hline
\end{tabular}

Notes: These statistics refer to second moments for annualized data obtained from Chari et al. (2002) for the period 1973-95 that has been logged and detrended using the HP filter. 
Table 2: Observed and Simulated Moments for IST Shocks Model

\begin{tabular}{lcccc}
\hline & Data & Benchmark & Mid-level EOS & High EO \\
\hline & & & & \\
Volatility: & & & & \\
Consumption & 0.9300 & 0.7043 & 0.6564 & 0.6443 \\
Investment & 2.6200 & 7.9132 & 7.8336 & 7.7850 \\
RER (CPI) & 5.0900 & 3.6342 & 2.8741 & 2.3505 \\
RER (PPI) & - & 4.6377 & 4.1219 & 3.7237 \\
Distribution Costs & - & 2.6715 & 2.4032 & 2.2217
\end{tabular}

Persistence:

$\begin{array}{lcccc}\text { Output } & 0.4900 & 0.9605 & 0.9614 & 0.9619 \\ \text { Consumption } & 0.5800 & 0.8256 & 0.8801 & 0.9144 \\ \text { Investment } & 0.4500 & 0.4598 & 0.4671 & 0.4716 \\ \text { RER (CPI) } & 0.6400 & 0.6006 & 0.5915 & 0.5871 \\ \text { RER (PPI) } & - & 0.5495 & 0.5405 & 0.5356 \\ \text { Distribution Costs } & - & 0.6006 & 0.5915 & 0.5871\end{array}$

\section{Cross-Correlation:}

$\begin{array}{lllll}\text { Output } & 0.6700 & 0.6204 & 0.6690 & 0.7000 \\ \text { Investment } & 0.1800 & 0.6866 & 0.6925 & 0.6996\end{array}$

Correlation with RER:

\begin{tabular}{lcccc} 
Output & 0.4100 & 0.4613 & 0.5001 & 0.5246 \\
Trade Balance & 0.4000 & 0.6143 & 0.6241 & 0.6318 \\
Relative Consumption & -0.3800 & -0.8734 & -0.8605 & -0.8530 \\
\hline
\end{tabular}

Notes: The second column refers to second moments for annualized data obtained from Chari et al. (2002) for the period 1973-98 that has been logged and detrended using the HP filter. The volatility statistics refer to the ratio of the standard deviation of the variables of interest divided by the standard deviation of GDP. 
Figure 1: Home Country's Response to a 1\% IST Shock, $\sigma_{i}=1.5$
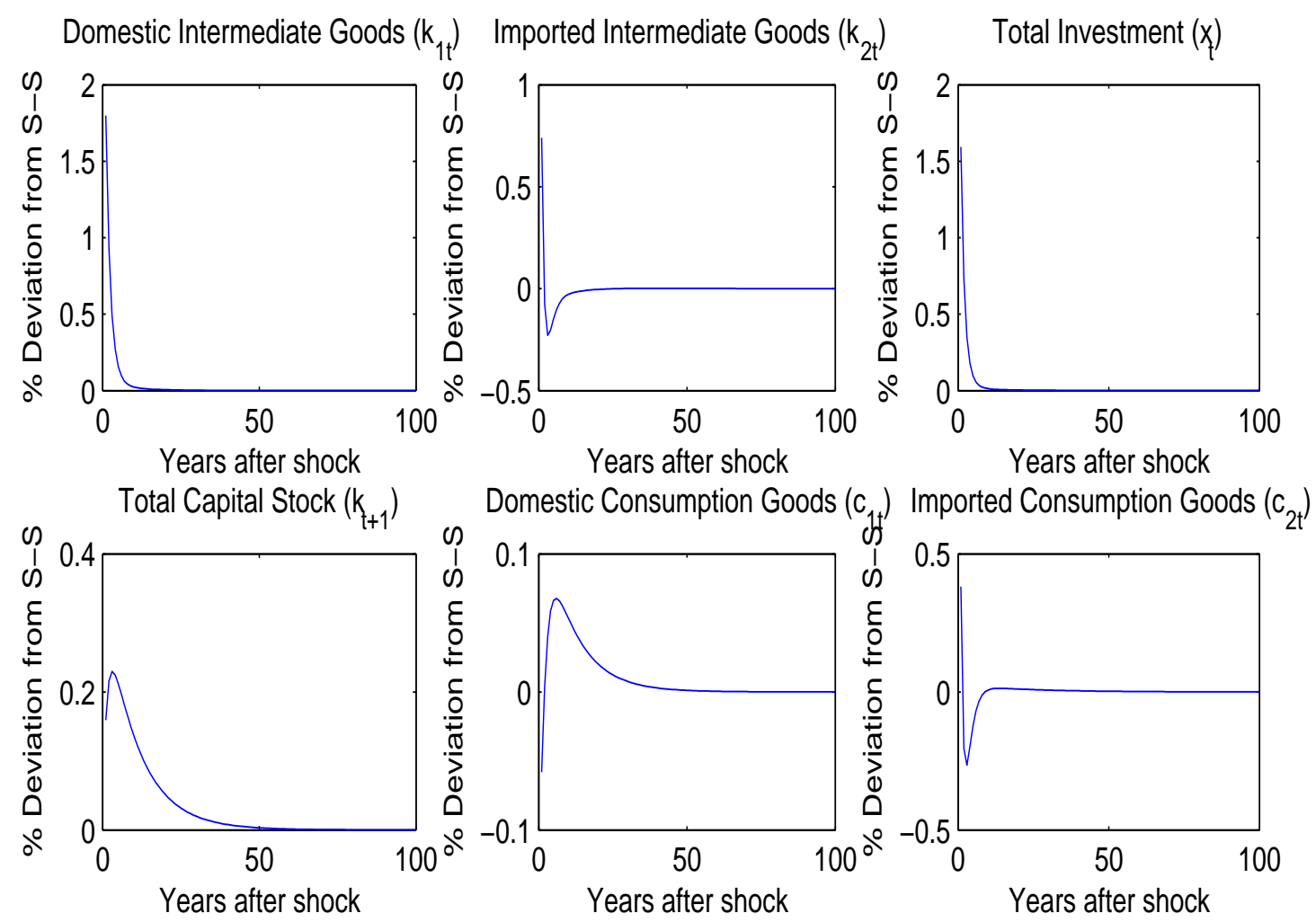

Total Domestic Consumption $\left(c_{\mathrm{t}}\right)$ Output of Distribution Services $\left(\mathrm{y}_{\mathrm{dt}}\right)$ Output of Consumption Goods $\left(\mathrm{y}_{\mathrm{ct}}\right)$
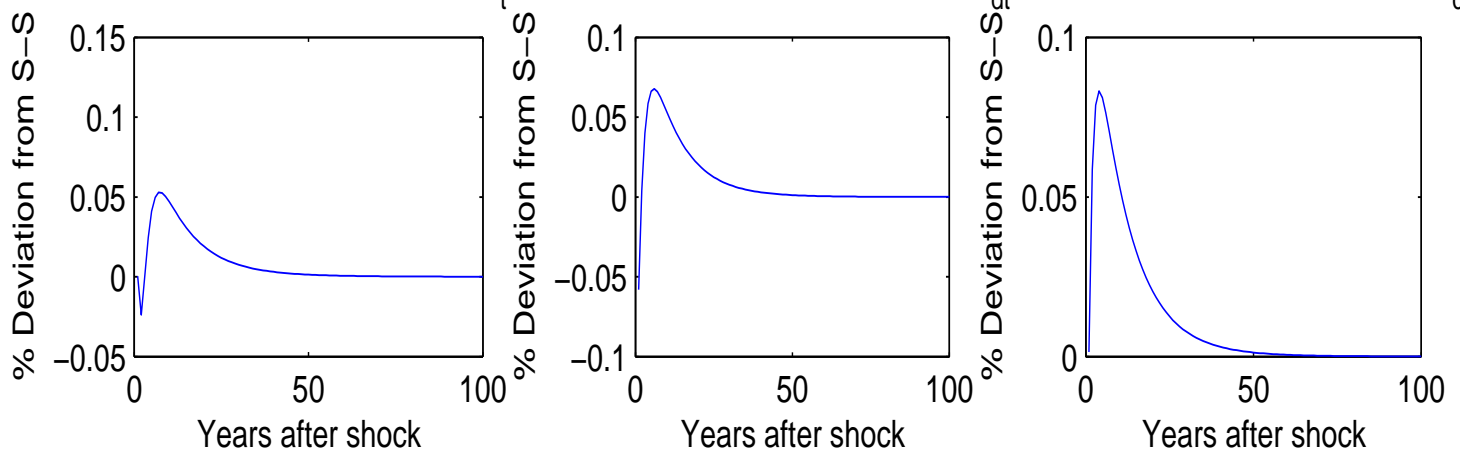
Figure 2: Foreign Country's Response to a $1 \%$ IST Shock, $\sigma_{i}=1.5$
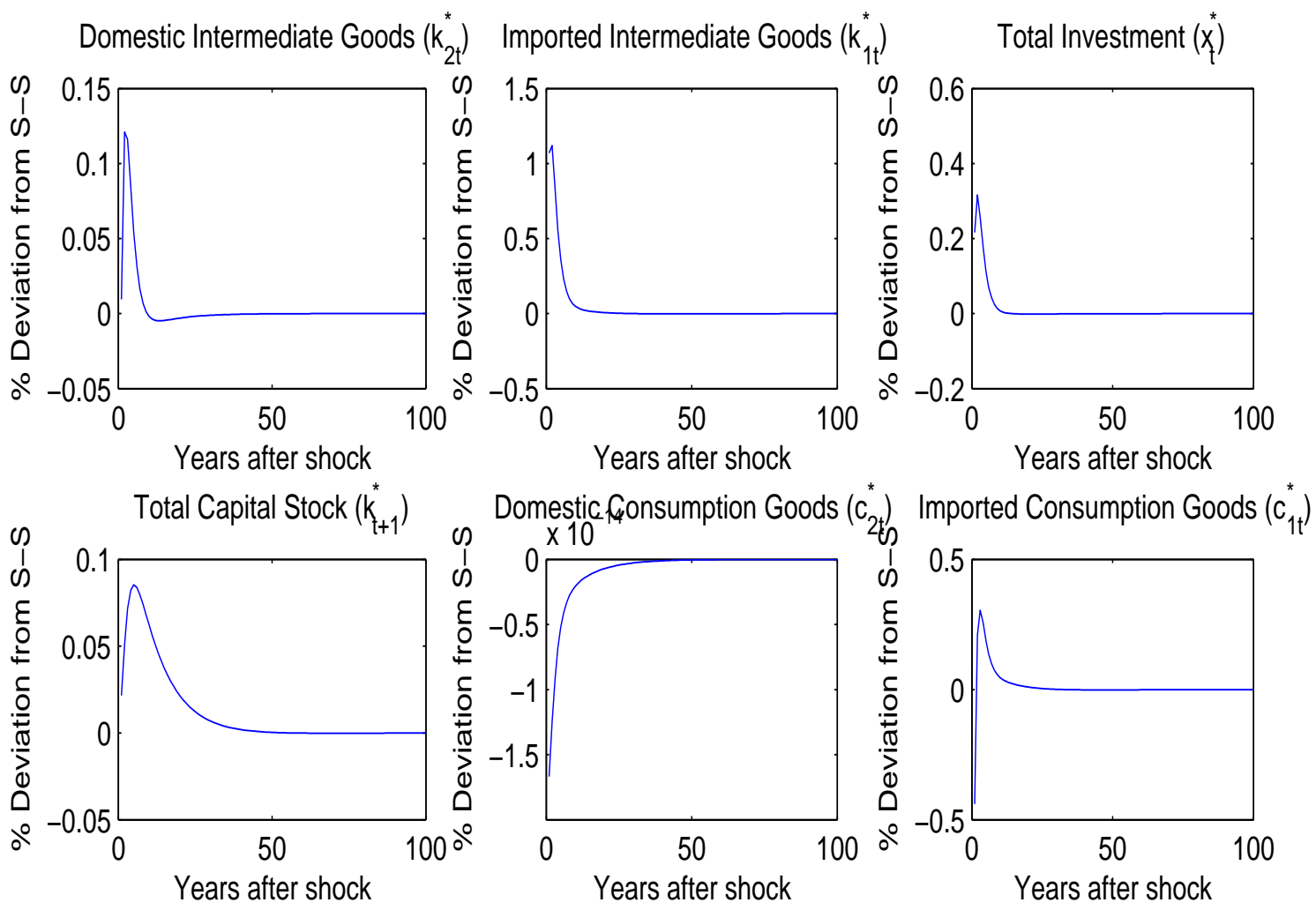

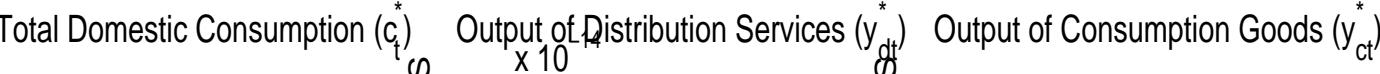
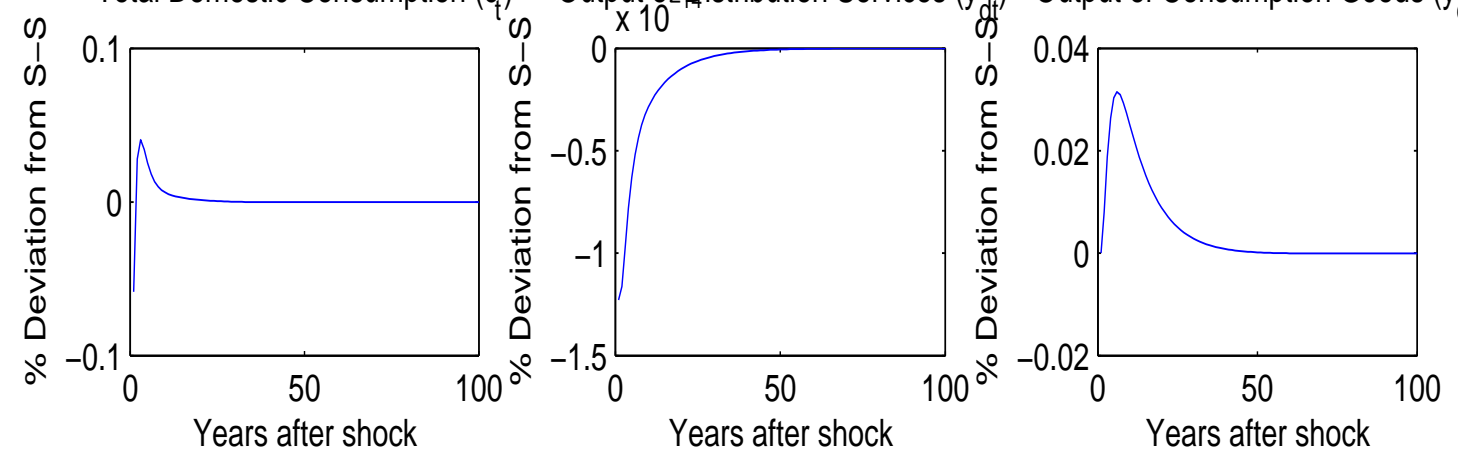
Figure 3: Response of Prices to a 1\% IST Shock, $\sigma_{i}=1.5$
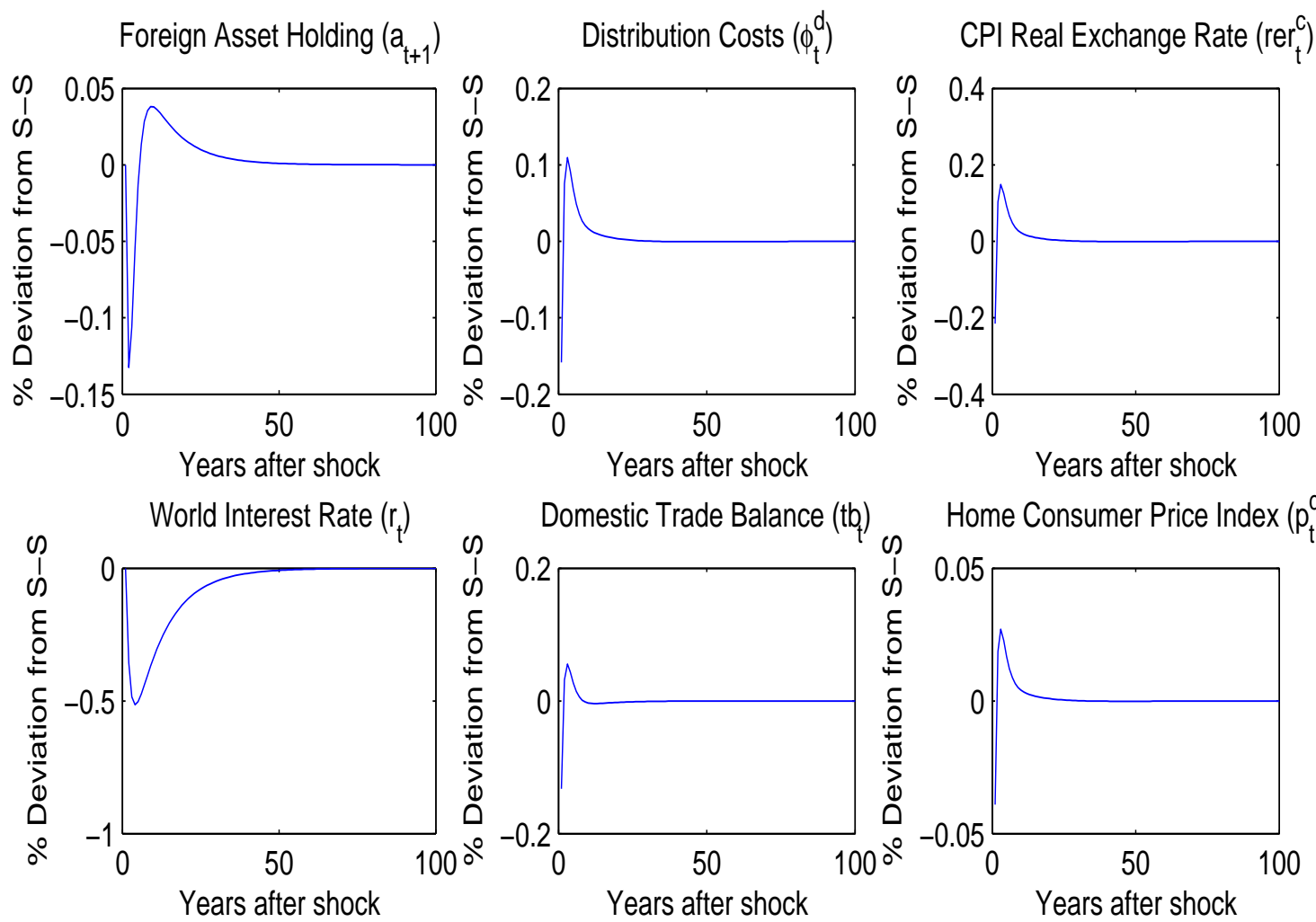

Domestic Trade Balance (tb)
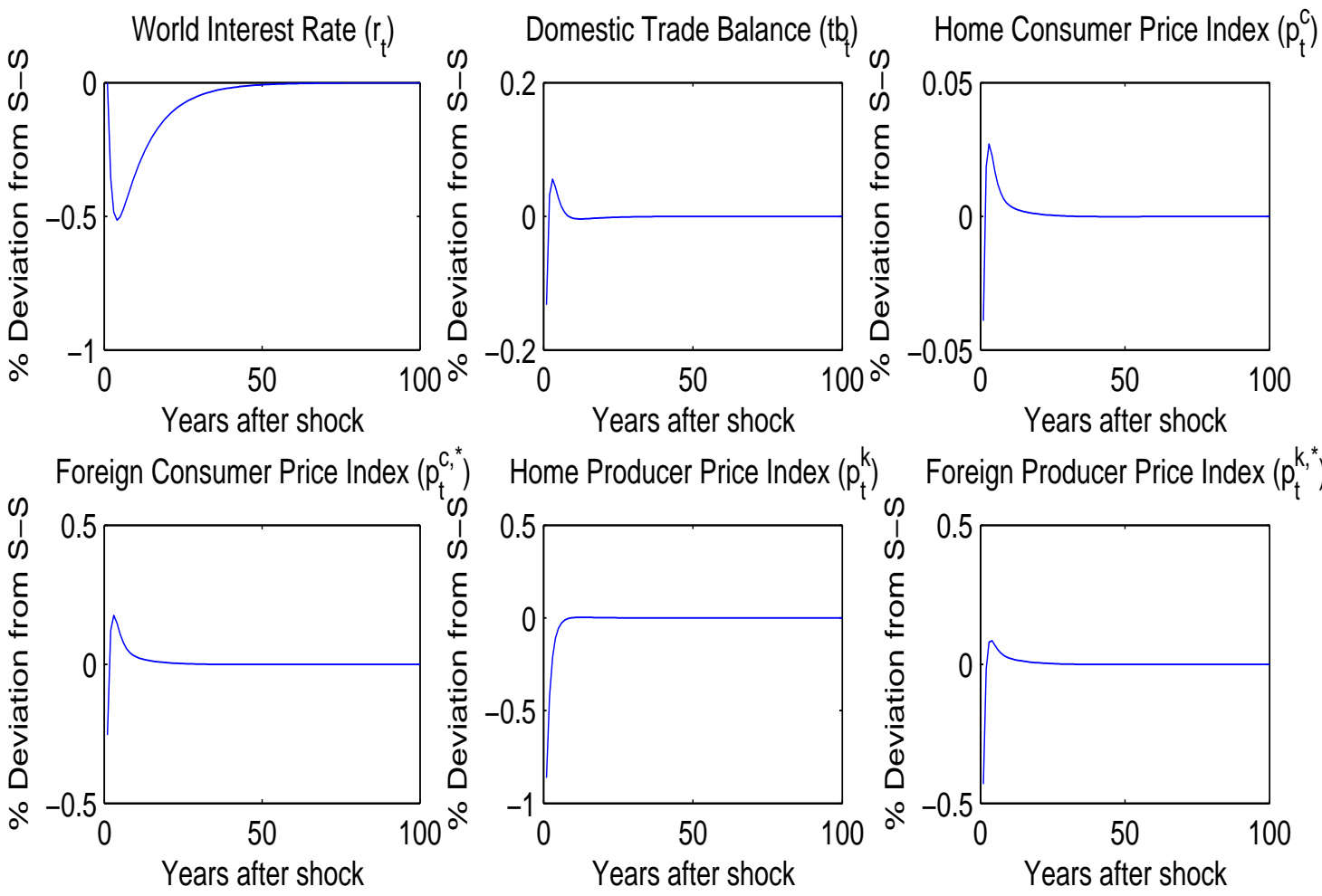
Table 3: Observed and Simulated Moments for IST Shocks Model Data: $\quad \sigma_{d}=1.45: \quad \sigma_{d}=1.55: \quad$ Model II*:

\section{Volatilities:}

$\begin{array}{lcccc}\text { Consumption } & 0.9300 & 0.7775 & 0.6701 & 0.6945 \\ \text { Investment } & 2.6200 & 8.0520 & 7.7883 & 3.8984 \\ \text { RER (CPI) } & 5.0900 & 4.2828 & 3.1114 & 0.1906 \\ \text { RER (PPI) } & - & 5.0628 & 4.3198 & 1.0506 \\ \text { Distribution Costs } & - & 3.1812 & 2.3597 & 1.2762\end{array}$

Persistence:

$\begin{array}{lcccc}\text { Output } & 0.4900 & 0.9589 & 0.9619 & 0.9920 \\ \text { Consumption } & 0.5800 & 0.7772 & 0.8632 & 0.9824 \\ \text { Investment } & 0.4500 & 0.4471 & 0.4701 & 0.8890 \\ \text { RER (CPI) } & 0.6400 & 0.5929 & 0.6068 & 0.7330 \\ \text { RER (PPI) } & - & 0.5516 & 0.5468 & 0.7450 \\ \text { Distribution Costs } & - & 0.5929 & 0.6068 & 0.9383\end{array}$

\section{Cross-Correlation:}

$\begin{array}{lllll}\text { Output } & 0.6700 & 0.5762 & 0.6500 & 0.7169 \\ \text { Investment } & 0.1800 & 0.6779 & 0.6918 & -0.4713\end{array}$

\section{Correlation with RER:}

\begin{tabular}{lrrrr} 
Output & 0.4100 & 0.4203 & 0.4893 & 0.7169 \\
Trade Balance & 0.4000 & 0.6166 & 0.6123 & -0.6568 \\
Relative Consumption & -0.3800 & -0.8854 & -0.8661 & -0.6568 \\
\hline
\end{tabular}

Notes: The second column refers to second moments for annualized data obtained from Chari et al. (2002) for the period 1973-98 that has been logged and detrended using the HP filter. The volatility statistics refer to the ratio of the standard deviation of the variables of interest divided by the standard deviation of GDP.

* Model without distribution service sector. 
Table 4: Steady-State Parameter Values:

\section{Parameters:}

\section{Definitions:}

\section{Benchmark:}

\begin{tabular}{|c|c|}
\hline$\beta=0.96$ & Constant annual discount factor \\
\hline$r_{t}=0.04$ & Steady-state annual world interest rate \\
\hline$\delta=0.10$ & Constant depreciation rate for Capital stock \\
\hline$\alpha=0.36$ & Share of capital services in production \\
\hline$\sigma_{c}=1.5$ & Elasticity of sub. between domestic and imported consumer goods \\
\hline$\sigma_{k}=1.5$ & Elasticity of sub. between domestic and foreign intermediate goods \\
\hline$\sigma_{d}=1.5$ & Elasticity of sub. between dist. svcs and foreign consumer goods \\
\hline$\omega_{c}=0.710$ & Share of domestic consumer goods \\
\hline$\omega_{d}=0.280$ & Share of distribution services \\
\hline$\omega_{k}=0.720$ & Share of domestic intermediate goods \\
\hline$\phi_{a}=0.50$ & Foreign assets adjustment costs \\
\hline$\phi_{k}=2.32$ & Capital adjustment costs \\
\hline
\end{tabular}

Mid-level Elasticity:

$\sigma_{i}=2.0$

Elasticity of sub. between goods

$\omega_{c}=0.634$

Share of domestic consumer goods

$\omega_{d}=0.308$

Share of distribution services

$\omega_{k}=0.670$

Share of domestic intermediate goods

\section{High Elasticity:}

$\sigma_{i}=2.5$

Elasticity of sub. between goods

$\omega_{c}=0.585$

Share of domestic consumer goods

$\omega_{d}=0.320$

Share of distribution services

$\omega_{k}=0.635$

Share of domestic intermediate goods 


\section{APPENDIX 1}

\section{A Derivations and Proofs}

\section{A.1 The Problem for the Decentralized Domestic Economy}

$$
\max _{\left\{a_{t+1}, c_{1 t}, c_{2 t}, i_{1 t}, i_{2 t}, k_{t+1}, k_{c t}, k_{d t}, l_{c t}, l_{d t}, c_{1 t}^{m}, y_{d t}\right\}} E_{t} \sum_{t=0}^{\infty} \beta^{t} \log \left(c_{t}\right), \quad 0<\beta<1
$$

s.t.

$$
\begin{aligned}
c_{1 t}+p_{2 t} c_{2 t}+p_{k t} i_{1 t}+p_{k t}^{*} i_{2 t}+t b_{t} & \leq y_{c t}-\left(\frac{\phi_{a}}{2}\right)\left(a_{t+1}-\bar{a}\right)^{2} \\
t b_{t} & =a_{t+1}-\left(1+r_{t}\right) a_{t} \\
l_{c t}+l_{d t} & \leq 1 \\
k_{c t}+k_{d t} & \leq k_{t} \\
k_{t+1} & =x_{t}+(1-\delta) k_{t}-\left(\frac{\phi_{k}}{2}\right)\left(k_{t+1}-k_{t}\right)^{2} \\
x_{t} & =\left[\omega_{k}\left(i_{1 t}\right)^{\eta_{k}}+\left(1-\omega_{k}\right)\left(i_{2 t}\right)^{\eta_{k}}\right]^{\frac{1}{\eta_{k}}} \\
c_{t} & =\left[\omega_{c}\left(c_{1 t}\right)^{\eta_{c}}+\left(1-\omega_{c}\right)\left(c_{1 t}^{m}\right)^{\eta_{c}}\right]^{\frac{1}{\eta_{c}}} \\
c_{1 t}^{m} & =\left[\omega_{d}\left(y_{d t}\right)^{\eta_{d}}+\left(1-\omega_{d}\right)\left(c_{2 t}\right)^{\eta_{d}}\right]^{\frac{1}{\eta_{d}}} \\
y_{c t} & =k_{c t}^{\alpha} l_{c t}^{(1-\alpha)} \\
y_{d t} & =k_{d t}^{\alpha} l_{d t}^{(1-\alpha)} \\
q_{t+1} & =\rho_{q} q_{t}+\rho_{q, q^{*}} q_{t}^{*}+\varepsilon_{t}^{q}
\end{aligned}
$$

\section{A.2 The FOCs}

Using $\lambda_{t}^{c}, \lambda_{t}^{l}, \lambda_{t}^{k}, \lambda_{t}^{x}, \lambda_{t}^{m}$ and $\lambda_{t}^{d}$ as the multipliers associated with Equation $36,38,39,40,43$ and $45 \mathrm{I}$ have the following first order condition with respect to $a_{t+1}, c_{1 t}, c_{1 t}^{m}, c_{2 t}, y_{d t}, k_{t+1}$, $i_{1 t}, i_{2 t}, k_{c t}, k_{d t}, l_{c t}$ and $l_{d t}$ :

$$
\begin{aligned}
\lambda_{t}^{c}\left[1+\phi_{a}\left(a_{t+1}-\bar{a}\right)\right] & =\beta E_{t} \lambda_{t+1}^{c}\left(1+r_{t+1}\right) \\
\lambda_{t}^{c} & =\omega_{c}\left(c_{1 t}\right)^{\eta_{c}-1}\left[\omega_{c}\left(c_{1 t}\right)^{\eta_{c}}+\left(1-\omega_{c}\right)\left(c_{1 t}^{m}\right)^{\eta_{c}}\right]^{-1} \\
\lambda_{t}^{m} & =\left(1-\omega_{c}\right)\left(c_{1 t}^{m}\right)^{\eta_{c}-1}\left[\omega_{c}\left(c_{1 t}\right)^{\eta_{c}}+\left(1-\omega_{c}\right)\left(c_{1 t}^{m}\right)^{\eta_{c}}\right]^{-1}
\end{aligned}
$$




$$
\begin{aligned}
\lambda_{t}^{c} p_{2 t} & =\lambda_{t}^{m}\left(1-\omega_{d}\right)\left(c_{2 t}\right)^{\eta_{d}-1}\left[\omega_{d}\left(d_{t}\right)^{\eta_{d}}+\left(1-\omega_{d}\right)\left(c_{2 t}\right)^{\eta_{d}}\right]^{\frac{1-\eta_{d}}{\eta_{d}}} \\
\lambda_{t}^{d} & =\lambda_{t}^{m} \omega_{d}\left(y_{d t}\right)^{\eta_{d}-1}\left[\omega_{d}\left(y_{d t}\right)^{\eta_{d}}+\left(1-\omega_{d}\right)\left(c_{2 t}\right)^{\eta_{d}}\right]^{\frac{1-\eta_{d}}{\eta_{d}}} \\
\lambda_{t}^{x}\left[1+\phi_{k}\left(k_{t+1}-k_{t}\right)\right] & =\beta E_{t}\left\{\lambda_{t+1}^{x}\left[(1-\delta)+\phi_{k}\left(k_{t+2}-k_{t+1}\right)\right]+\lambda_{t+1}^{k}\right\} \\
\lambda_{t}^{c} p_{k t} & =\lambda_{t}^{x} \omega_{k}\left(i_{1 t}\right)^{\eta_{k}-1}\left[\omega_{k}\left(i_{1 t}\right)^{\eta_{k}}+\left(1-\omega_{k}\right)\left(i_{2 t}\right)^{\eta_{k}}\right]^{\frac{1-\eta_{k}}{\eta_{k}}} \\
\lambda_{t}^{c} p_{k t}^{*} & =\lambda_{t}^{x}\left(1-\omega_{k}\right)\left(i_{2 t}\right)^{\eta_{k}-1}\left[\omega_{k}\left(i_{1 t}\right)^{\eta_{k}}+\left(1-\omega_{k}\right)\left(i_{2 t}\right)^{\eta_{k}}\right]^{\frac{1-\eta_{k}}{\eta_{k}}} \\
\lambda_{t}^{k} & =\lambda_{t}^{c} \alpha \frac{y_{c t}}{k_{c t}} \\
\lambda_{t}^{k} & =\lambda_{t}^{d} \alpha \frac{y_{d t}}{k_{c t}} \\
\lambda_{t}^{l} & =\lambda_{t}^{c}(1-\alpha) \frac{y_{c t}}{l_{c t}} \\
\lambda_{t}^{l} & =\lambda_{t}^{d}(1-\alpha) \frac{y_{d t}}{l_{d t}}
\end{aligned}
$$

\section{A.3 Deterministic Steady State Conditions}

Symmetry in the two economies ensures that $p_{2 t}=p_{1 t}=1$, similarly, given that $q_{t}=q_{t}^{*}=1$ in steady-state, I must also have $t b_{t}=0$ and $a_{t}=a_{t+1}=0$. In steady-state I have $\lambda_{t}^{i}=\lambda_{t+1}^{i}=\lambda^{i}$ $\forall i$, which implies that $\beta(1+r)=1$.

From Equation 48, 53, 54 and 56:

$$
r+\delta=\alpha \frac{y}{k_{c}} \omega_{k}\left(i_{1}\right)^{\eta_{k}-1}\left[\omega_{k}\left(i_{1}\right)^{\eta_{k}}+\left(1-\omega_{k}\right)\left(i_{2}\right)^{\eta_{k}}\right]^{\frac{1-\eta_{k}}{\eta_{k}}}
$$

From Equation 48, 51, 52, 53, 54 and 58:

$$
r+\delta=\alpha \frac{y_{d}}{k_{d}}\left(\frac{\omega_{d}}{1-\omega_{d}}\right)\left(\frac{c_{2}}{y_{d}}\right)^{\eta_{d}-1} \omega_{k}\left(i_{1}\right)^{\eta_{k}-1}\left[\omega_{k}\left(i_{1}\right)^{\eta_{k}}+\left(1-\omega_{k}\right)\left(i_{2}\right)^{\eta_{k}}\right]^{\frac{1-\eta_{k}}{\eta_{k}}}
$$

From Equation 51, 52, 58 and 59:

$$
\left(\frac{y_{d}}{y_{c}}\right)\left(\frac{l_{c}}{l_{d}}\right)=\left(\frac{1-\omega_{d}}{\omega_{d}}\right)\left(\frac{y_{d}}{c_{2}}\right)^{1-\eta_{d}}
$$

From Equation 54 and 55:

$$
\frac{i_{1}}{i_{2}}=\left[\frac{\omega_{k}}{1-\omega_{k}}\right]^{\frac{1}{1-\eta_{k}}}
$$

From Equation 49, Eq. 50 and 51:

$$
\frac{c_{1}}{c_{1}^{m}}=\left[\left(\frac{1-\omega_{c}}{\omega_{c}}\right)\left(1-\omega_{d}\right)\left[\omega_{d}\left(\frac{y_{d}}{c_{2}}\right)^{\eta_{d}}+\left(1-\omega_{d}\right)\right]^{\frac{1-\omega_{d}}{\omega_{d}}}\right]^{\frac{1}{\eta_{c}-1}}
$$


To complete the deterministic steady-state conditions I have the following constraints:

$$
\begin{aligned}
l_{c}+l_{d} & =1 \\
k_{c}+k_{d} & =k \\
\omega_{k}\left(\frac{i_{1}}{i_{2}}\right)^{\eta_{k}}+\left(1-\omega_{k}\right) & =\left(\frac{\delta k}{i_{2}}\right)^{\eta_{k}} \\
\omega_{d}\left(\frac{y_{d}}{c_{2}}\right)^{\eta_{d}}+\left(1-\omega_{d}\right) & =\left(\frac{c_{1}^{m}}{c_{2}}\right)^{\eta_{d}} \\
\frac{y_{d}}{k_{d}} & =\left(\frac{k_{d}}{l_{d}}\right)^{\alpha-1} \\
\frac{y_{c}}{k_{c}} & =\left(\frac{k_{c}}{l_{c}}\right)^{\alpha-1} \\
y_{c} & =c_{1}+c_{2}+i_{1}+i_{2}
\end{aligned}
$$

To fully calibrate the steady-state I have a system of 12 equations and 12 unknown. The unknowns I need to solve for are: $y_{c}, k_{c}, k_{d}, l_{c}, l_{d}, k, i_{1}, i_{2}, y_{d}, c_{1}, c_{2}$, and $c_{1}^{m}$. We use the factor price equalization condition in both the labor and capital markets to obtain $\frac{y_{d}}{c_{2}}=\left(\frac{\omega_{d}}{1-\omega_{d}}\right)^{\frac{1}{1-\eta_{d}}}$ and $\frac{k_{d}}{l_{d}}=k=\frac{k_{c}}{l_{c}}$. These two conditions, along with the value of $\frac{i_{1}}{i_{2}}$ can then be used to obtain the remaining variables of interest. 